\title{
A pilot study of change in fracture risk in patients with acute respiratory distress syndrome
}

\author{
Jaikitry Rawal ${ }^{1}$, Mark JW McPhail ${ }^{2,3}$, Gamumu Ratnayake ${ }^{4}$, Pearl Chan ${ }^{1}$, John Moxham ${ }^{5}$, Stephen DR Harridge ${ }^{6+}$, \\ Nicholas Hart ${ }^{4 \dagger}$, Hugh E Montgomery ${ }^{1+}$ and Zudin A Puthucheary ${ }^{1,7^{*+}}$
}

\begin{abstract}
Introduction: Acute skeletal muscle wasting is a major contributor to post critical illness physical impairment. However, the bone response remains uncharacterized. We prospectively investigated the early changes in bone mineral density (BMD) and fracture risk in critical illness.

Methods: Patients were prospectively recruited $\leq 24$ hours following intensive care unit (ICU) admission to a university teaching or a community hospital (August 2009 to April 2011). All were aged $>18$ years and expected to be intubated for $>48$ hours, spend $>7$ days in critical care and survive ICU admission. Forty-six patients were studied (55.3\% male), with a mean age of 54.4 years ( $95 \%$ confidence interval (Cl): 49.1 to 59.6) and an APACHE II score of 23.9 (95\% Cl: 22.4 to 25.5). Calcaneal dual X-ray absorptiometry (DXA) assessment of BMD was performed on day 1 and 10. Increase in fracture risk was calculated from the change in T-score.

Results: BMD did not change between day 1 and 10 in the cohort overall (0.434 (95\% Cl: 0.405 to 0.463 ) versus $0.425 \mathrm{~g} / \mathrm{cm}^{2}$ (95\% Cl: 0.399 to 0.450), $P=0.58$ ). Multivariable logistical regression revealed admission corrected calcium (odds ratio (OR): 1.980 (95\% Cl: 1.089 to 3.609), $P=0.026)$ and admission $\mathrm{PaO}_{2}$-to-FiO 2 ratio (OR: 0.916 (95\% Cl: 0.833 to 0.998$), P=0.044$ ) to be associated with $>2 \%$ loss of BMD. Patients with acute respiratory distress syndrome had a greater loss in BMD than those without $(-2.81 \%$ ( $95 \% \mathrm{Cl}:-5.73$ to $0.118 \%), \mathrm{n}=34$ versus $2.40 \%$ ( $95 \% \mathrm{Cl}: 0.204$ to $4.586 \%), \mathrm{n}=12, P=0.029$ ). In the 34 patients with acute respiratory distress syndrome, fracture risk increased by $19.4 \%$ (95\% Cl: 13.9 to $25.0 \%)$.
\end{abstract}

Conclusions: Patients with acute respiratory distress syndrome demonstrated early and rapid bone demineralisation with associated increase in fracture risk.

\section{Introduction}

Rapid and early muscle wasting contributes to the significant long-term functional impairment observed in survivors of critical illness [1-4]. Although muscle and bone mass correlate in healthy individuals [5-7], there are limited data reporting the impact of critical illness on bone health. During acute critical illness, mechanical unloading as a consequence of bed rest [8], inflammation [9], acidaemia [10], vitamin D deficiency [11], corticosteroid use [12] and hypoxia [13] may all worsen bone health and reduce bone mineral density (BMD).

\footnotetext{
* Correspondence: Zudin_amilka_puthucheary@nuhs.edu.sg

${ }^{\dagger}$ Equal contributors

${ }^{1}$ Institute of Health and Human Performance, University College London,

Room 443, 74 Huntley Street, London WC1E 6AU, UK

${ }^{7}$ Division of Respiratory and Critical Care, National University Hospital, $1 \mathrm{E}$

Lower Kent Ridge Road, Singapore 119228, Singapore

Full list of author information is available at the end of the article
}

Indeed, markers of bone turnover increase during critical illness $[11,14]$. Such bone demineralization may explain symptoms of generalised musculoskeletal pain in survivors of critical illness [1,2], and the reported increase in fracture risk in elderly females following critical illness [15]. However, the bone response to critical illness has never before been prospectively studied. We thus performed a pilot study to investigate the early effects of critical illness on BMD and fracture risk, and also sought clinical factors that might be associated with early bone demineralization.

\section{Materials and methods}

Subjects comprised a subgroup of the Musculoskeletal Ultrasound in Critical Illness: Longitudinal Evaluation cohort (trial registered with Clinicaltrials.gov, identifier: NCT01106300) [4]. Ethical approval was obtained from 
the University College London ethics committee. Patients were recruited within 24 hours of admission to a university hospital (Kings College Hospital NHS Foundation Trust) or a community hospital intensive (Whittington Hospital NHS Trust) care unit (ICU) between August 2009 and April 2011. All were anticipated to be invasively ventilated for more than 48 hours, spend more than 7 days in the ICU and survive their ICU stay. Patients who were pregnant or suffering lower limb amputation, primary neuromuscular disease or cancer were excluded. At enrolment, written assent was obtained from the next-of-kin, with retrospective patient consent obtained when full mental capacity was regained.

BMD was assessed using dual X-ray absorptiometry (DXA) imaging on day 1 and day 10 (DXL Calscan, Demetech AB, Sweden), which has a coefficient of variance of $0.9 \%$. Fracture risk was calculated from a change in T-score whereby the relative risk of a major osteoporotic fracture increases 1.5 -fold (95\% confidence interval (CI): 1.4 to 1.6) per standard deviation below the mean T-score [16]. Detailed clinical and physiological bedside data were collected, as previously described [4].

\section{Statistical analysis}

All data were assessed for normality using D'Agostino and Pearson omnibus normality tests, and analyzed using Student's t-test, Pearson's coefficient, Mann-Whitney U test and Wilcoxon's signed rank tests, as appropriate. For the purposes of hypothesis generation in this pilot study, we sought a parsimonious model of associated physiological factors. Age, sex and chronic disease were forced into bivariable logistical regression (Statistical Package for the Social Sciences version 17; SPSS Inc., Chicago, IL, USA) using a threshold of $2 \%$ loss of BMD, which is twice the expected loss from bed rest alone [8]. Statistically significant independent variables from the bivariable analysis were entered into a backward multivariable analysis if the $P$ value was 0.10 or less.

\section{Results}

Fifty-seven patients assented to serial DXA scanning. Of these, seven did not survive ten days, one was transferred to another hospital, one withdrew from the study, one was discharged before day ten and one was unable to have serial scans for technical reasons. Forty-six patients were included in the final analysis. The characteristics of these 46 patients, shown in Table 1, did not differ from those withdrawn, except for a higher Simplified Acute Physiology Score (SAPS II) (40.9 (95\% CI: 37.5 to $44.3, \mathrm{n}=46$ ) versus 53.3 ( $95 \% \mathrm{CI}: 44.2$ to $62.4, \mathrm{n}=10$ ); $P<0.01$ ). Four patients had pre-morbid conditions associated with possible disrupted calcium homeostasis (one with hypothyroidism, one with Crohn's disease, two with hyperthyroidism). Their baseline DXA measurement was no different from the remaining cohort $(0.387 \pm 0.07$ versus $0.437 \pm 0.01$,
Table 1 Characteristics of patients who had serial measurements versus those who only had admission measurements

\begin{tabular}{|c|c|c|c|}
\hline & $\begin{array}{l}\text { Serial DEXA } \\
\text { measurements }\end{array}$ & $\begin{array}{l}\text { Single DEXA } \\
\text { measurement }\end{array}$ & $P$ value \\
\hline $\mathrm{N}$ & 46 & 11 & - \\
\hline Age & $55.09(49.9-60.3)$ & $53.9(40.6-67.1)$ & 0.93 \\
\hline Male sex, $\mathrm{n}(\%)^{\mathrm{b}}$ & $26(55.3)$ & $6(60)$ & 0.74 \\
\hline Pre-ICU LOS & $1(1-45)$ & $1(1-6)$ & 0.25 \\
\hline APACHE II score & $24(22.4-25.6)$ & $27.1(21.9-32.3)$ & 0.12 \\
\hline SAPS II score & $40.9(37.5-44.3)$ & $53.3(44.2-62.4)$ & $<0.01^{\mathrm{c}}$ \\
\hline Admission SOFA score & $9.3(8.5-10.0)$ & $8.6(5.8-11.4)$ & 0.50 \\
\hline \multicolumn{4}{|l|}{ Admission diagnosis, n (\%) } \\
\hline Cardiogenic shock & $6(13.0)$ & $3(33.3)$ & \\
\hline Trauma & $12(26.1)$ & $2(20.0)$ & \\
\hline Acute renal failure & $1(2.2)$ & $2(20.0)$ & \\
\hline Intra cranial haemorrhage & $5(10.9)$ & $1(10.0)$ & \\
\hline Acute liver failure & $4(8.7)$ & $1(10.0)$ & \\
\hline Severe sepsis & $16(34.8)$ & $1(10.0)$ & \\
\hline Major haemorrhage & $2(4.3)$ & $0(0.0)$ & \\
\hline \multicolumn{4}{|l|}{ Co-morbidities, n (\%) } \\
\hline Ischaemic heart disease & $5(10.9)$ & $3(33.3)$ & \\
\hline Liver cirrhosis & $6(13.0)$ & $0(0.0)$ & \\
\hline Haematological disease & $2(4.3)$ & $1(10.0)$ & \\
\hline Hypertension & $9(19.6)$ & $1(10.0)$ & \\
\hline Obesity & $2(4.3)$ & $0(0.0)$ & \\
\hline COPD & $7(15.2)$ & $0(0.0)$ & \\
\hline Diabetes mellitus & $5(10.9)$ & $0(0.0)$ & \\
\hline Previous CVA & $1(2.2)$ & $0(0.0)$ & \\
\hline Chronic pancreatitis & $1(2.2)$ & $0(0.0)$ & \\
\hline Thyroid disease & $3(6.5)$ & $0(0.0)$ & \\
\hline Crohn's disease & $1(2.2)$ & $0(0.0)$ & \\
\hline Renal impairment & $2(4.3)$ & $0(0.0)$ & \\
\hline Small bowel insufficiency & $0(0.0)$ & $1(10.0)$ & \\
\hline
\end{tabular}

APACHE II = Acute Physiology and Chronic Health Evaluation II, COPD = Chronic Obstructive Pulmonary Disease, $C V A=$ Cerebro Vascular Accident, DEXA = Dual X-ray Absorptiometry, ICU = Intensive Care Unit, LOS = Length of Stay, SAPS II = Simplified Acute Physiology Score, SOFA = Sequential Organ Failure Assessment.

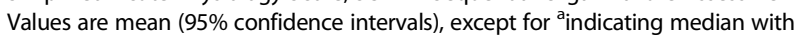
range. Student's T-test was used except for ${ }^{\mathrm{b}}$ (chi-squared) and ${ }^{\mathrm{a}}$ (Mann Whitney $U)$ )' indicates $P<0.05$.

$P=0.350$ ). Twenty eight patients $(61 \%)$ were defined as having osteopenia on day one of the study; however, no patients received renal replacement therapy using citrate anticoagulation with calcium replacement, and no subjects received regular selective serotonin reuptake inhibitors or serotonin norepinephrine reuptake inhibitors (associated with lower BMD) prior to critical illness. Further data regarding recruitment and survival, as well as baseline laboratory values, are available in Additional file 1. 
Table 2 Bivariable and multivariable logistical analysis of bedside physiology versus $2 \%$ loss of bone mineral density by day 10

\begin{tabular}{|c|c|c|c|c|c|c|}
\hline \multirow[b]{2}{*}{ Variable } & \multirow[b]{2}{*}{ OR } & \multicolumn{2}{|l|}{ Univariate } & \multirow[b]{2}{*}{ OR } & \multicolumn{2}{|l|}{$\underline{\text { Multivariate }}$} \\
\hline & & $95 \% \mathrm{Cl}$ & $P$ value & & $95 \% \mathrm{Cl}$ & $P$ value \\
\hline Admission BMD & 1.000 & $0.997-1.003$ & 0.899 & & & \\
\hline Change in $\mathrm{RF}_{\mathrm{CSA}}$ & 1.019 & $0.971-1.070$ & 0.439 & & & \\
\hline Organ failure & 1.078 & $1.005-1.157$ & $0.037^{\mathrm{g}}$ & & & \\
\hline Age & 0.980 & $0.946-1.015$ & 0.268 & 0.977 & $0.939-1.059$ & 0.935 \\
\hline $\mathrm{CRP}^{\mathrm{a}}$ & 1.000 & $0.999-1.001$ & 0.857 & & & \\
\hline Chronic disease $\mathrm{e}^{\mathrm{e}}$ & 1.385 & $0.417-4.602$ & 0.595 & 1.266 & $0.167-9.596$ & 0.819 \\
\hline Insulin ${ }^{a, b}$ & 1.046 & $0.937-1.167$ & 0.421 & & & \\
\hline Protein ${ }^{a, b}$ & 1.034 & $0.941-1.136$ & 0.491 & & & \\
\hline Calories $^{\mathrm{a}, \mathrm{b}}$ & 1.007 & $0.996-1.017$ & 0.220 & & & \\
\hline $\mathrm{LMWH}^{\mathrm{f}}$ & 1.001 & $0.998-1.004$ & 0.530 & & & \\
\hline Unfractionated heparin ${ }^{f}$ & 1.000 & $1.000-1.000$ & 0.518 & & & \\
\hline All heparin ${ }^{f}$ & 1.000 & $1.000-1.000$ & 0.725 & & & \\
\hline Male sex & 1.711 & $0.499-5.871$ & 0.393 & 4.966 & $0.567-43.567$ & 0.147 \\
\hline APACHE ॥ & 1.050 & $0.937-1.176$ & 0.403 & & & \\
\hline SAPS ॥ & 0.995 & $0.944-1.050$ & 0.867 & & & \\
\hline Admission SOFA & 1.080 & $0.846-1.381$ & 0.536 & & & \\
\hline Temperature & 0.788 & $0.489-1.270$ & 0.328 & & & \\
\hline Haemoglobin & 1.047 & $0.794-1.381$ & 0.744 & & & \\
\hline White cell count & 0.886 & $0.778-1.009$ & 0.068 & & & \\
\hline Platelets & 0.994 & $0.988-1.000$ & 0.053 & & & \\
\hline INR & 4.960 & $0.886-27.774$ & 0.068 & & & \\
\hline APTTR & 2.830 & $0.403-19.873$ & 0.296 & & & \\
\hline Sodium & 0.988 & $0.871-1.121$ & 0.856 & & & \\
\hline Potassium & 0.475 & $0.160-1.411$ & 0.180 & & & \\
\hline Urea & 0.999 & $0.891-1.121$ & 0.992 & & & \\
\hline Creatinine & 1.001 & $0.990-1.011$ & 0.914 & & & \\
\hline Alkaline phosphatase & 1.010 & $0.995-1.025$ & 0.178 & & & \\
\hline AST & 1.003 & $0.999-1.006$ & 0.097 & & & \\
\hline Bilirubin & 1.048 & $0.998-1.101$ & 0.061 & 1.078 & $0.994-1.156$ & 0.076 \\
\hline Albumin & 1.027 & $0.944-1.117$ & 0.539 & & & \\
\hline Calcium ${ }^{g}$ & 1.974 & $1.116-3.492$ & $0.020^{9}$ & 1.980 & $1.089-3.609$ & 0.026 \\
\hline Phosphate & 0.653 & $0.195-2.191$ & 0.491 & & & \\
\hline Magnesium & 0.435 & $0.036-5.190$ & 0.510 & & & \\
\hline $\mathrm{PaO}_{2}$ & 0.836 & $0.659-1.061$ & 0.141 & & & \\
\hline $\mathrm{SaO}_{2}$ & 0.840 & $0.617-1.145$ & 0.271 & & & \\
\hline $\mathrm{PaCO}_{2}$ & 0.943 & $0.600-1.482$ & 0.798 & & & \\
\hline $\mathrm{H}^{+}$ & 1.000 & $0.993-1.006$ & 0.960 & & & \\
\hline Base excess & 0.967 & $0.812-1.151$ & 0.706 & & & \\
\hline Bicarbonate & 1.024 & $0.839-1.249$ & 0.815 & & & \\
\hline Lactate & 1.018 & $0.669-1.549$ & 0.933 & & & \\
\hline Chloride & 1.047 & $.0935-1.172$ & 0.424 & & & \\
\hline Apparent SID & 0.914 & $.0792-1.055$ & 0.218 & & & \\
\hline
\end{tabular}


Table 2 Bivariable and multivariable logistical analysis of bedside physiology versus $2 \%$ loss of bone mineral density by day 10 (Continued)

\begin{tabular}{|c|c|c|c|c|c|c|}
\hline Effective SID & 0.641 & $0.933-1.118$ & 0.641 & & & \\
\hline Strong ion gap & 0.968 & $0.905-1.035$ & 0.338 & & & \\
\hline Glucose day 1 & 0.923 & $0.622-1.370$ & 0.692 & & & \\
\hline MAP & 1.010 & $0.947-1.077$ & 0.768 & & & \\
\hline Heart rate & 0.994 & $0.960-1.029$ & 0.735 & & & \\
\hline $\mathrm{PaO}_{2} / \mathrm{FiO}_{2}$ ratio & 0.943 & $0.890-1.000$ & $0.050^{9}$ & 0.916 & $0.833-0.998$ & 0.044 \\
\hline SIRS & 0.544 & $0.154-1.925$ & 0.345 & & & \\
\hline NMB use & 1.154 & $0.742-1.795$ & 0.524 & & & \\
\hline Corticosteroid use $e^{c}$ & 1.000 & $1.000-1.001$ & 0.856 & & & \\
\hline RRT & 1.094 & $0.291-4.109$ & 0.894 & & & \\
\hline HMGCoA use ${ }^{d}$ & 2.000 & $0.483-8.275$ & 0.339 & & & \\
\hline Median glucose $\mathrm{e}^{\mathrm{a}}$ & 1.158 & $0.637-2.104$ & 0.631 & & & \\
\hline Days of intubation & 0.988 & $0.923-1.057$ & 0.724 & & & \\
\hline LOS pre-admission & 1.166 & $0.681-1.994$ & 0.576 & & & \\
\hline
\end{tabular}

Organ failure was defined by SOFA scoring. All values are for day 1 of ICU admission, except ${ }^{\text {a }}$ which denotes area under curve for 10 days. ${ }^{b}$ Indicates those normalised to ideal body weight. ${ }^{\mathrm{C} C o r t i c o s t e r o i d ~ d o s e s ~ c a l c u l a t e d ~ i n ~ h y d r o c o r t i s o n e ~ e q u i v a l e n t s . ~}{ }^{\mathrm{d}}$ Denotes use on admission, and continued through study period. ${ }^{\mathrm{e}}$ Chronic disease defined by hospital and general practice coding for management of chronic disease. ${ }^{\mathrm{f}}$ Indicates cumulative dose. ${ }^{\mathrm{g}} \mathrm{calcium}$ variable, exponentially transformed to allow logistic regression. Bold type indicates $P<0.05$.

APACHE II = Acute Physiology and Chronic Health Evaluation II score, APTTR = Activated partial thromboplastin time ratio, AST = Aspartate transaminase, CRP = C-reactive protein, $\mathrm{FiO}_{2}=$ Fraction of inspired oxygen, $\mathrm{HMGCoA} \mathrm{RI}=3$-hydroxy-3-methyl-glutaryl-CoA reductase inhibitor treatment, INR = International normalised ratio, $\mathrm{LMWH}=$ Low molecular weight heparin, $\mathrm{LOS}=$ Length of stay, $\mathrm{NMB}=$ Neuromuscular blockade, $\mathrm{PaCO}_{2}=$ Partial pressure of carbon dioxide in arterial blood, $\mathrm{PaO} \mathrm{O}_{2}=\mathrm{Partial}$ pressure of oxygen in arterial blood, $\mathrm{RF}_{\mathrm{CSA}}=$ Rectus Femoris cross-sectional area in 10 days, $\mathrm{RRT}=$ Renal replacement therapy, $\mathrm{SaO}_{2}=\mathrm{Oxygen}_{\mathrm{sat}} \mathrm{sation}$ in arterial blood, $\mathrm{SAPS} 2=$ Simplified Acute Physiology Score 2, SID = Strong lon Difference, SOFA = Sequential Organ Failure Assessment.

\section{Clinical associations with change in bone mass density}

BMD data were non-normally distributed prior to and following log transformation. There was no change in BMD between day 1 and 10 in the cohort overall (0.434 (95\% CI: 0.405 to 0.463 ) versus $0.425 \mathrm{~g} / \mathrm{cm}^{2}$ (95\% CI: 0.399 to $0.450), P=0.58)$. Multivariable logistical regression, adjusted for age, sex and chronic disease, was performed using a threshold of $2 \%$ loss of BMD. The model (overall model fit $P<0.001$, Hosmer-Lemeshow test $P=0.90$, Table 2) demonstrated that admission calcium corrected for serum albumin (odds ratio (OR): 1.980 (95\% CI: 1.089 to 3.609$), P=0.026)$ and the ratio of arterial partial pressure of oxygen $\left(\mathrm{PaO}_{2}\right)$ to fraction of inspired oxygen $\left(\mathrm{FiO}_{2}\right)$ on admission (OR: 0.916 (95\% CI: 0.833 to 0.998$)$, $P=0.044$ ) were associated with a greater than $2 \%$ loss of BMD. Patient with acute respiratory distress syndrome (ARDS) $\left(\mathrm{PaO}_{2-}\right.$ to- $\mathrm{FiO}_{2}$ ratio of less than $300 \mathrm{mmHg}$ [17] demonstrated greater BMD loss than those without ( $-2.81 \%$ (95\% CI: -5.73 to $0.118 \%), \mathrm{n}=34$ versus $2.40 \%$ (95\% CI: 0.204 to $4.586 \%), \mathrm{n}=12, P=0.029$ ).

\section{Change in T-score}

Admission T-score in those with ARDS did not differ from those without $(-1.259$ (95\% CI: -1.737 to -0.781$)$, $\mathrm{n}=34$ versus -1.325 (95\% CI: -1.969 to -0.681 ), $\mathrm{n}=12$, $P=0.617)$, but ARDS patients had a change in T-score from day 1 to day 10 ( -1.259 (95\% CI: -1.737 to -0.781 ), $\mathrm{n}=34$ versus -1.518 (95\% CI: -1.922 to -1.114$), P=0.047)$ compared to those without $(-1.325$ (95\% CI: -1.969 to -0.681$)$ versus -1.200 (95\% CI: -1.798 to -0.602 ), $P=0.101)$. In the 34 patients with ARDS, fracture risk increased by $19.4 \%$ (95\% CI: 13.9 to $25.0 \%$ ) in the first 10 days of critical illness in comparison to those without (9.35\% (95\% CI: -2.1 to $20.9 \%), P=0.012$, Figure 1 ).

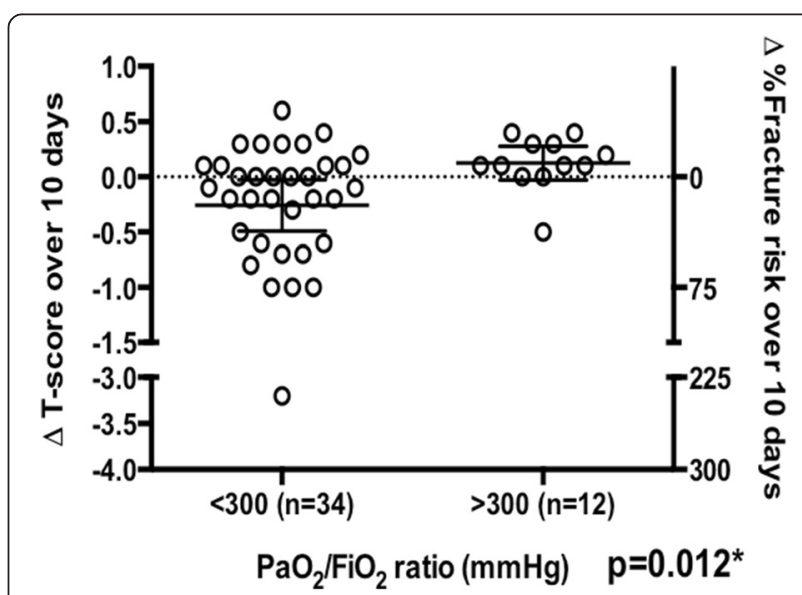

Figure 1 Change in T-score and percentage increase in fracture risk in patients with $(n=34)$ and without $(n=12)$ acute respiratory distress syndrome. $\mathrm{FiO}_{2}=$ Fraction of inspired oxygen, $\mathrm{PaO}_{2}=$ Partial pressure of oxygen in blood. Mann-Whitney $U$ test was performed between groups, ${ }^{*} P<0.05$. 


\section{Discussion}

\section{Clinical relevance}

The relationship between loss of BMD and rise in serum calcium concentration is to be expected. However, rapid early bone demineralization, of similar magnitude to that observed after much more prolonged weightlessness in space [18], occurs rapidly and early in critically ill patients with ARDS. The association of ARDS with bone demineralization is physiologically plausible: ARDS results in systemic release of inflammatory cytokines [19] such as interleukin-6 [20], TNF $\alpha$ [20,21], interleukin-1 [21] and interleukin-8 [22], which stimulate osteoclastogenesis and bone resorption with calcium mobilized into the circulation from these bone stores [23]. The scale of this loss is associated with an increase in calculated prospective fracture risk; an issue of some importance given that ARDS survivors have a number of independent risk factors for falls [24], including accelerated skeletal muscle wasting [4] and marked loss of executive function [25]. Bone is certainly able to respond rapidly to remodelling forces: changes are observed within 15 to 21 days in rodent models of unloading [26,27], and markers of bone turnover alter with single bouts of exercise in humans [28]. However, we are unaware of studies of the human skeletal response to illness over timeframes a short as that which we have addressed. Whilst in vitro evidence exists that hypoxia is detrimental to skeletal physiology and has both an inhibitory effect on osteoblastogenesis [29] and an activator-enhancing effect on osteoclastogenesis [30], no relationship was seen with admission hypoxia, although intermittent hypoxia as a stimulus cannot be excluded.

\section{Limitations}

Whilst acknowledging that the first day of ICU admission is not the first day of critical illness, the median time to ICU admission was 24 hours, and 23 patients were admitted after a sudden acute event (for example trauma, myocardial infarction or intracranial bleed) with no antecedent decline. Nonetheless, these data should be considered hypothesis-generating. The limited sample size also precludes detailed exploration of other risk factors, such as osteopaenia, and generalisation to specific patient groups. Regrettably, we are unable to determine whether the observed changes translated into clinical skeletal events, given that this pilot study was not funded for the post-discharge follow-up of patients. Larger observational cohort studies, with extended follow-up periods, are required to determine the impact of critical illness on BMD and actual fracture risk. The determination of calcaneal BMD using DXA is valid and comparable to hip and spine DXA in determining fracture risk [16,31], and is more readily performed than the assessment of spine and hip bone densitometry in a remote imaging facility during the early stage of critical illness when the patient is most unstable. The coefficient of variance of DXA measures was $0.9 \%$. A loss of more than $2 \%$ in calcaneal BMD (as we sought) was thus likely to represent true loss as opposed to measurement error.

\section{Conclusions}

Rapid bone demineralization, associated with an increase in fracture risk, was observed in critically ill patients with ARDS. More extensive and extended hypothesisdriven epidemiological cohort studies are required to confirm this finding, and to determine whether bone demineralisation represents a new therapeutic target in reducing morbidity following critical illness.

\section{Key messages}

- Loss of bone mineral density occurs rapidly in critically ill patients with acute respiratory distress syndrome.

- This is likely to be associated with an increase in fracture risk.

\section{Additional file}

Additional file 1: Supplementary data. 1.1 Baseline laboratory data. 1.2 Flowchart of patient recruitment and survival within study.

\section{Abbreviations}

ARDS: Acute Respiratory Distress Syndrome; BMD: Bone Mineral Density; $\mathrm{Cl}$ : Confidence interval; DXA: Dual X-ray Absorptiometry; $\mathrm{FiO}_{2}$ : Fraction of inspired oxygen; ICU: Intensive Care Unit; OR: Odds ratio; $\mathrm{PaO}_{2}$ : Arterial partial pressure of oxygen; SAPS II: Simplified acute physiology score; TNFa: tumor necrosis factor alpha.

\section{Competing interests}

The authors declare that they have no competing interests.

\section{Authors' contributions}

Concept and design: JR, JM, SH, NH, HM, and ZP. Data collection: JR, MM, GR, $P C$, and ZP. Analysis and interpretation: JR, MM, GR, PC, HM, and ZP. Manuscript drafting and revision: JR, MM, GR, JM, SH, NH, HE, and ZP. All authors read and approved the final manuscript.

\section{Acknowledgements}

ZP is funded by the National Institute of Health Research (NIHR) UK. This research was supported by the NIHR University College London Hospitals Biomedical Research Centre (BRC). Additional funding was received from the European Society of Intensive Care Medicine, Guy's and St Thomas' and King's College London NIHR Comprehensive Biomedical Research Centre and the Whittington Hospital NHS Trust. MM is funded by the Wellcome Trust UK and acknowledges the BRC at Imperial College and King's College London for infrastructure support. This paper was supported by Grant Number, DRF-2010-03-114.

The NIHR, the European Society of Intensive Care Medicine, Guy's and St Thomas' and King's College London NIHR Comprehensive BRC and the Whittington Hospital NHS Trust had no role in the design and conduct of the study; collection, management, analysis and interpretation of the data; preparation, review or approval of the manuscript; or decision to submit the manuscript for publication.

The authors are grateful to the patients and staff at both King's College Hospital and the Whittington Hospital NHS trust, without which this study could not have been performed. ZP has full access to all data in the study and takes responsibility for the integrity of the data and the accuracy of the data analysis. 


\section{Author details}

${ }^{1}$ Institute of Health and Human Performance, University College London, Room 443, 74 Huntley Street, London WC1E 6AU, UK. Department of Hepatology and Gastroenterology, St Mary's Hospital, Imperial College London, praed street, London W2 1NY, UK. 'Institute of Liver Studies, King's College Hospital NHS Foundation Trust, denmark hill, London SE59RS, UK ${ }^{4} \mathrm{NIHR}$ Comprehensive Biomedical Research Centre, Guy's and St Thomas' NHS Foundation Trust and King's College London, Westminster Bridge Road, London SE17EH, UK. 'King's College London School of Medicine, denmark hill, London SE59RS, UK. ${ }^{6}$ Centre of Human and Aerospace Physiological Sciences, King's College London, Great Maze Pond, London SE1 9RT, UK ${ }^{7}$ Division of Respiratory and Critical Care, National University Hospital, $1 \mathrm{E}$ Lower Kent Ridge Road, Singapore 119228, Singapore.

Received: 19 January 2015 Accepted: 20 March 2015

\section{Published online: 14 April 2015}

\section{References}

1. Herridge MS, Tansey CM, Matté A, Tomlinson G, Diaz-Granados N, Cooper A, et al. Functional disability 5 years after acute respiratory distress syndrome. N Engl J Med. 2011;364:1293-304.

2. Herridge MS, Cheung AM, Tansey CM, Matte-Martyn A, Diaz-Granados N, Al-Saidi $\mathrm{F}$, et al. One-year outcomes in survivors of the acute respiratory distress syndrome. N Engl J Med. 2003;348:683-93.

3. Iwashyna TJ. Survivorship will be the defining challenge of critical care in the 21st century. Ann Intern Med. 2010;153:204-5.

4. Puthucheary ZA, Rawal J, McPhail M, Connolly B, Ratnayake G, Chan P, et al. Acute skeletal muscle wasting in critical illness. JAMA. 2013;310:1591-600.

5. Chen JH, Liu C, You L, Simmons CA. Boning up on Wolff's Law: mechanical regulation of the cells that make and maintain bone. J Biomech. 2010;43:108-18.

6. Lang TF. The bone-muscle relationship in men and women. J Osteoporos. 2011:2011:702735.

7. Schoenau E. From mechanostat theory to development of the "Functional Muscle-Bone-Unit". J Musculoskelet Neuronal Interact. 2005:5:232-8.

8. Krolner B, Toft B. Vertebral bone loss: an unheeded side effect of therapeutic bed rest. Clin Sci (Lond). 1983:64:537-40.

9. Bertolini DR, Nedwin GE, Bringman TS, Smith DD, Mundy GR. Stimulation of bone resorption and inhibition of bone formation in vitro by human tumour necrosis factors. Nature. 1986;319:516-8.

10. Bushinsky DA, Smith SB, Gavrilov KL, Gavrilov LF, Li J, Levi-Setti R. Acute acidosis-induced alteration in bone bicarbonate and phosphate. Am J Physiol Renal Physiol. 2002;283:F1091-7.

11. Van den Berghe G, Van Roosbroeck D, Vanhove P, Wouters PJ, De Pourcq L, Bouillon R. Bone turnover in prolonged critical illness: effect of vitamin D. J Clin Endocrinol Metab. 2003;88:4623-32.

12. Dubois EF, Roder E, Dekhuijzen PN, Zwinderman AE, Schweitzer DH. Dual energy $\mathrm{X}$-ray absorptiometry outcomes in male COPD patients after treatment with different glucocorticoid regimens. Chest. 2002;121:1456-63.

13. Uzkeser $\mathrm{H}$, Yildirim $\mathrm{K}$, Aktan B, Karatay S, Kaynar H, Araz O, et al. Bone mineral density in patients with obstructive sleep apnea syndrome. Sleep Breath. 2013;17:339-42.

14. Smith LM, Cuthbertson B, Harvie J, Webster N, Robins S, Ralston SH. Increased bone resorption in the critically ill: association with sepsis and increased nitric oxide production. Crit Care Med. 2002;30:837-40.

15. Orford NR, Saunders K, Merriman E, Henry M, Pasco J, Stow P, et al. Skeletal morbidity among survivors of critical illness. Crit Care Med. 2011;39:1295-300.

16. Cummings SR, Bates D, Black DM. Clinical use of bone densitometry: scientific review. JAMA. 2002;288:1889-97.

17. Ranieri VM, Rubenfeld GD, Thompson BT, Ferguson ND, Caldwell E, Fan E, et al. Acute respiratory distress syndrome: the Berlin Definition. JAMA. 2012;307:2526-33.

18. Lang T, LeBlanc A, Evans H, Lu Y, Genant H, Yu A. Cortical and trabecular bone mineral loss from the spine and hip in long-duration spaceflight. J Bone Miner Res. 2004;19:1006-12.

19. Goodman RB, Pugin J, Lee JS, Matthay MA. Cytokine-mediated inflammation in acute lung injury. Cytokine Growth Factor Rev. 2003;14:523-35.

20. Ding C, Parameswaran V, Udayan R, Burgess J, Jones $G$. Circulating levels of inflammatory markers predict change in bone mineral density and resorption in older adults: a longitudinal study. J Clin Endocrinol Metab. 2008:93:1952-8.
21. Boyle WJ, Simonet WS, Lacey DL. Osteoclast differentiation and activation. Nature. 2003;423:337-42.

22. Bendre MS, Montague DC, Peery T, Akel NS, Gaddy D, Suva LJ. Interleukin-8 stimulation of osteoclastogenesis and bone resorption is a mechanism for the increased osteolysis of metastatic bone disease. Bone. 2003;33:28-37.

23. Lieben L, Masuyama R, Torrekens S, Van Looveren R, Schrooten J, Baatsen P, et al. Normocalcemia is maintained in mice under conditions of calcium malabsorption by vitamin D-induced inhibition of bone mineralization. J Clin Invest. 2012;122:1803-15.

24. Bagshaw SM, Stelfox HT, McDermid RC, Rolfson DB, Tsuyuki RT, Baig N, et al. Association between frailty and short- and long-term outcomes among critically ill patients: a multicentre prospective cohort study. CMAJ. 2014;186:E95-E102.

25. Pandharipande PP, Girard TD, Jackson JC, Morandi A, Thompson JL, Pun BT, et al. Long-term cognitive impairment after critical illness. N Engl J Med. 2013;369:1306-16.

26. Zhang B, Cory E, Bhattacharya R, Sah R, Hargens AR. Fifteen days of microgravity causes growth in calvaria of mice. Bone. 2013;56:290-5.

27. Sun LW, Luan HQ, Huang YF, Wang Y, Fan YB. Effects of local vibration on bone loss in -tail-suspended rats. Int J Sports Med. 2014;35:615-24.

28. Sherk VD, Chrisman C, Smith J, Young KC, Singh H, Bemben MG, et al. Acute bone marker responses to whole-body vibration and resistance exercise in young women. J Clin Densitom. 2013;16:104-9.

29. Nicolaije C, Koedam M, van Leeuwen JP. Decreased oxygen tension lowers reactive oxygen species and apoptosis and inhibits osteoblast matrix mineralization through changes in early osteoblast differentiation. J Cell Physiol. 2012;227:1309-18.

30. Dandajena TC, Ihnat MA, Disch B, Thorpe J, Currier GF. Hypoxia triggers a HIF-mediated differentiation of peripheral blood mononuclear cells into osteoclasts. Orthod Craniofac Res. 2012;15:1-9.

31. Muschitz C, Dimai HP, Kocijan R, Kaider A, Zendeli A, Kuhne F, et al. The discriminatory capacity of BMD measurements by DXA and dual X-ray and laser (DXL) at the calcaneus including clinical risk factors for detecting patients with vertebral fractures. Osteoporos Int. 2013;24:2181-90.

\section{Submit your next manuscript to BioMed Central and take full advantage of:}

- Convenient online submission

- Thorough peer review

- No space constraints or color figure charges

- Immediate publication on acceptance

- Inclusion in PubMed, CAS, Scopus and Google Scholar

- Research which is freely available for redistribution 